\title{
Stroke Note
}

\section{Cerebrovascular Diseases}

Cerebrovasc Dis 2013;36:158-159

DOI: $10.1159 / 000353664$

\section{Reversible Cerebral Vasoconstriction Syndrome after Chewing Khat Leaves}

Anil M. Tuladhara , Hieronymus D. Boogaarts ${ }^{\text {b }}$, Frank-Erik de Leeuwa, Ewoud van Dijk ${ }^{\mathrm{a}}$

a Department of Neurology, Donders Institute for Brain, Cognition and Behavior, Centre for Neuroscience, and

${ }^{b}$ Department of Neurosurgery, Radboud University Nijmegen Medical Centre, Nijmegen, The Netherlands

\section{Introduction}

A 26-year-old Eritrean man was referred to our clinic with severe sudden-onset episodic throbbing headache and photophobia. Medical history revealed severe depression which was treated with tranylcypromine $10 \mathrm{mg} /$ day, a monoamine oxidase (MAO) inhibitor, due to unsuccessful trials with first-line agents. He also men-
Received: April 28, 2013 Accepted: June 11, 2013 tioned chewing khat leaves for recreational usage. Neurologic examination was unremarkable. CT and MRI revealed frontal and occipital subarachnoidal hemorrhage (fig. 1a, b). CT angiography and MR angiography (MRA) showed no abnormalities. Catheter angiography, performed 3 days later, revealed segmental narrowing of multiple cerebral arteries, most prominently in the distal part of the left anterior cerebral artery (fig. 1c). We suspected reversible cerebral vasoconstriction syndrome (RCVS) caused by khat in combination with an MAO inhibitor. Several hours after the angiography, the patient complained about a sudden severe pain in the neck and between the shoulders. Neurological examination was still unremarkable. Repeated MRI of head and neck and MRA of aorta and cervical vessels showed increased signal intensity in the cervico-thoracal myelum on the FLAIR image (fig. 1d) and the gadolinium-enhanced T1-weighted image in the cervical myelum and no signs of arterial dissection. Blood tests and cerebral spinal fluid analyses were normal. The patient was temporarily treated with paracetamol and morphine by continuous infusion and was later switched to oxycodon and nimodipine. His symp-
Fig. 1. a Transversal CT showing cortical subarachnoidal hemorrhage (right frontal). b Transversal (FLAIR) cerebral MRI showing a subarachnoidal hyperintense signal (left occipital) suggestive of cortical subarachnoidal hemorrhage. c Catheter angiography showing narrowing of the distal branches of the anterior and middle cerebral artery. d Sagittal (FLAIR) cervical MRI showing a hyperintense signal in the cervico-thoracal myelum.
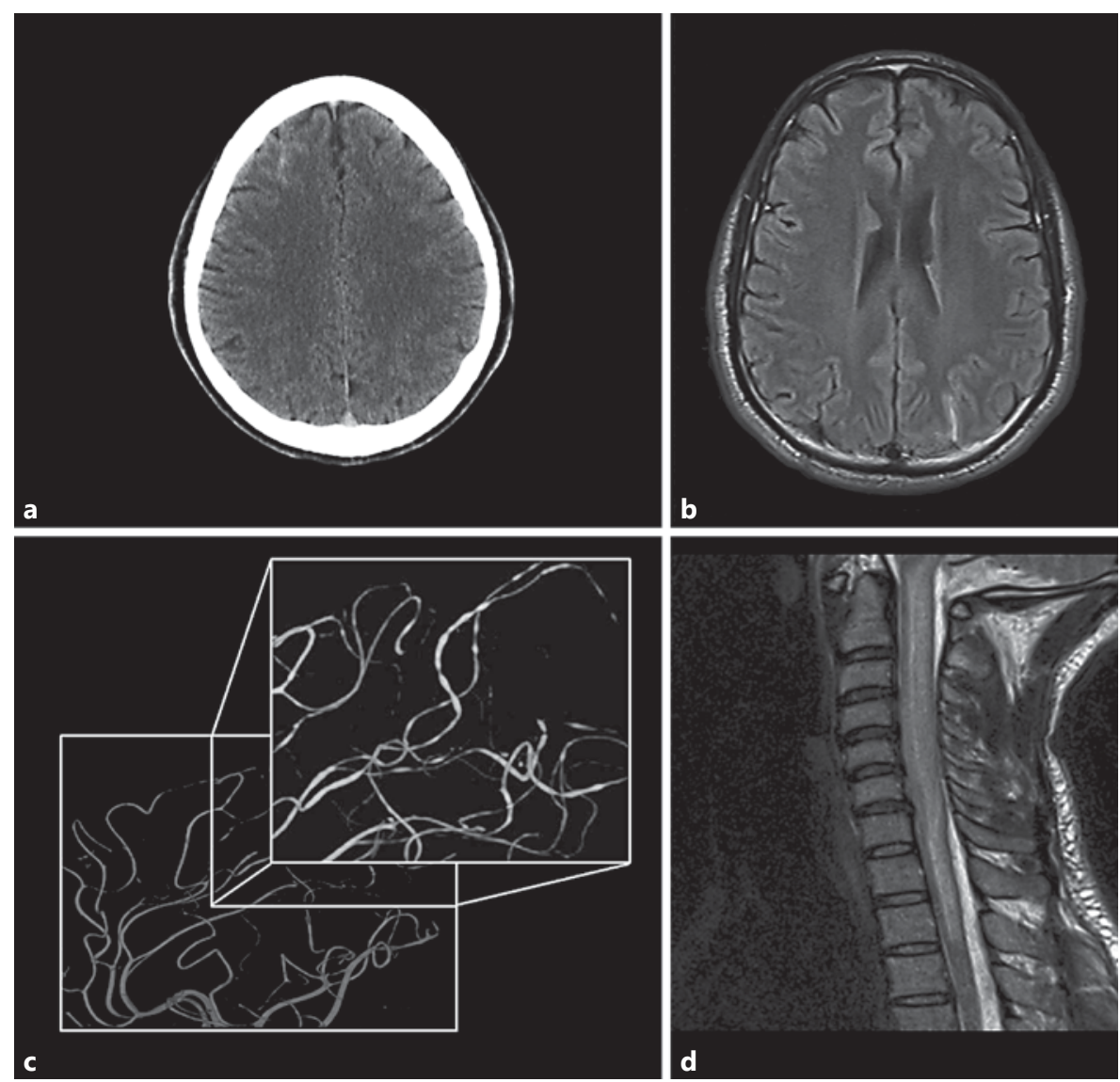

\section{KARGER}

E-Mail karger@karger.com www.karger.com/ced
(C) 2013 S. Karger AG, Basel

1015-9770/13/0362-0158\$38.00/0
Dr. Ewoud van Dijk

Donders Institute for Brain, Cognition and Behavior, Centre for Neuroscience Department of Neurology, Radboud University Nijmegen Medical Centre PO Box 9101, NL-6500 HB Nijmegen (The Netherlands)

E-Mail E.vanDijk@neuro.umcn.nl 
toms gradually resolved and a follow-up MRI after 3 months showed clear resolution of the earlier abnormalities. Cessation of khat usage and abstinence from other vasoactive substances was advised.

\section{Discussion}

RCVS is characterized by a recurrent thunderclap headache with or without neurological symptoms resulting from multifocal narrowing of the cerebral arteries, which resolves spontaneously within 3 months $[1,2]$. Major sequelae are cortical subarachnoidal hemorrhages, posterior reversible leukoencephalopathy, and ischemic and hemorrhagic stroke [3]. More than half of the cases are secondary, mostly due to exposure to vasoactive substances and/ or to the postpartum state [3]. Catha edulis (khat) is a flowering plant chewed by millions mainly in Africa and the Middle East for its stimulant effects. Cathinone and cathine, the main active psychostimulant constituents of khat, have sympathomimetic actions and vasoconstrictor activity. No earlier publications have reported khat chewing as a cause of RCVS. Theoretically, when used together with an MAO inhibitor, increased sympathetic stimulation can be induced, eventually leading to cerebral vasoconstriction [5] and in this case RCVS. Tranylcypromine is an irreversible nonselective MAO inhibitor which is reserved as third- or fourth-line treatment for major depression in most guidelines due to safety and tolerability [4]. This is also the first report to describe spinal abnormalities. One explanation might be that khat combined with an MAO inhibitor causes a more extensive subtype of RCVS. The other explanation is that the temporal relationship between con- ventional angiography and the reversible swelling of cervical myelum suggests some type of vulnerability of the blood vessels towards contrast agent exposure during angiography. One case series reported a transient neurological deficit after angiography in $9 \%$ of the patients with RCVS [3]. Treatment of RCVS usually consists of analgesics, antiepileptic drugs if indicated, monitoring blood pressure, nimodipine, and discontinuation of vasoactive substance usage [1]. RCVS should be considered in patients with sudden-onset headache, and a search for exogenous vasoactive factors is essential. This case illustrates that RCVS can be caused by khat in combination with an MAO inhibitor and that spinal abnormalities might be a part of the RCVS spectrum.

Disclosure Statement

None.

\section{References}

1 Ducros A, Bousser MG: Reversible cerebral vasoconstriction syndrome. Pract Neurol 2009;9:256-267.

2 Calabrese LH, Dodick DW, Schwedt TJ, Singhal AB: Narrative review: reversible cerebral vasoconstriction syndromes. Ann Intern Med 2007; 146:34-44.

-3 Ducros A, Boukobza M, Porcher R, Sarov M, Valade D, Bousser MG: The clinical and radiological spectrum of reversible cerebral vasoconstriction syndrome: a prospective series of 67 patients. Brain 2007;130:3091-3101.

4 Thase ME: MAOIs and depression treatment guidelines. J Clin Psychiatry 2012;73:e24.

5 Cox G, Rampes H: Adverse effects of khat: a review. Adv Psychiatr Treat 2003;9:456-463. 